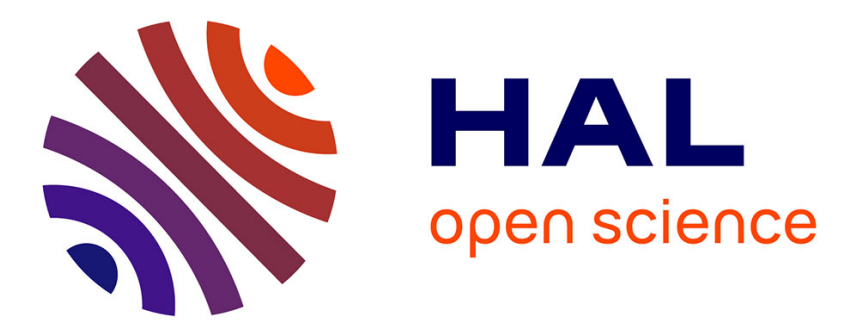

\title{
Towards Smart City Learning: Contextualizing Geometry Learning with a Van Hiele Inspired Location-Aware Game
}

Matthias Rehm, Catalin Stan, Niels Peter Wøldike, Dimitra Vasilarou

\section{To cite this version:}

Matthias Rehm, Catalin Stan, Niels Peter Wøldike, Dimitra Vasilarou. Towards Smart City Learning: Contextualizing Geometry Learning with a Van Hiele Inspired Location-Aware Game. 14th International Conference on Entertainment Computing (ICEC), Sep 2015, Trondheim, Norway. pp.399-406, 10.1007/978-3-319-24589-8_32. hal-01758470

\author{
HAL Id: hal-01758470 \\ https://hal.inria.fr/hal-01758470
}

Submitted on 4 Apr 2018

HAL is a multi-disciplinary open access archive for the deposit and dissemination of scientific research documents, whether they are published or not. The documents may come from teaching and research institutions in France or abroad, or from public or private research centers.
L'archive ouverte pluridisciplinaire HAL, est destinée au dépôt et à la diffusion de documents scientifiques de niveau recherche, publiés ou non, émanant des établissements d'enseignement et de recherche français ou étrangers, des laboratoires publics ou privés. 


\title{
Towards Smart City Learning: Contextualizing Geometry Learning with a Van Hiele Inspired Location-Aware Game
}

\author{
Matthias Rehm, Catalin Stan, Niels Peter Wøldike, and Dimitra Vasilarou \\ Aalborg University, Dept. of Architecture, Design, and Media Technology, 9000 \\ Aalborg, Denmark, matthias@create.aau.dk
}

\begin{abstract}
We present an approach to geometry learning that is based on play. For a mobile and location-aware game, the concept of smart city learning is exploited to situate learning about geometric shapes in concrete buildings and thus make them more accessible for younger children. A game was developed in close collaboration with a local school and tested on a field trip and in class. A mixed measures evaluation is presented, where the quantitative results show a significant increase in correct answers in a standardized test and the qualitative analysis reveals increased motivation and curiosity for geometric concepts.
\end{abstract}

Keywords: Smart City Learning; Location-Aware Games

\section{Introduction}

The notion of smart cities has been around for quite some time, but is often restricted to infrastructure or mobility aspects and does not focus on the actual users of a smart city. It is our conviction that the city itself can become the key element in creating smart learning environments that transcend traditional institutionalized learning by bringing learning back to where it originally belonged: everywhere. The work presented in this paper is related to our project on Smart Cities for Smart Children. The vision is to create a public space for learning experiences that transcend into all areas of the children's life by the use of modern mobile technology while at the same time establishing traditional institutions (like schools, libraries, museums, etc.) as hubs for information gathering and collaborative interactions. Learning is thus not confined to a traditional institutional setting but the children's living environment, i.e. the city itself, becomes an enchanted place allowing for discovering hidden knowledge in a playful manner. Smart cities, in our vision, become creative environments for realizing new ways of interacting with information (and with others), integrating real and virtual as well as social and emotional aspects.

In this paper we focus on STEM education, more precisely on primary school geometry learning. Based on Van Hiele's didactic approach (e.g. [4]) and in close collaboration with a local school, we developed a learning game that is on the one hand integrated into the city scape surrounding the school and at the same time into the Math curriculum at the school. 


\section{Related Work}

Smart City Learning The idea of smart city learning ${ }^{1}$ is currently emerging as a research field and derives its motivation from the fact that esp. in Europe a rich cultural heritage can often only be experienced in a de-contextualized fashion (e.g. in museums) although it is deeply rooted in the corresponding urban scapes (e.g. [3]). Although primarily focused on cultural heritage and the museal field, the vision is very attractive for every type of location-, or more generally, context-aware system aiming at providing knowledge or skills to the user. The vision of smart city learning puts these approaches in a broader theoretical perspective, emphasizing the necessity of in-situ interactions with the learning content. In this respect, [2] present an analysis of the situated learning that happens on field trips and make suggestions at which points in the experience smart city technologies could become situated tools for initiating actions, triggering reflections, or relating learning episodes across contexts. In [5], a case study is presented that highlights the beneficial effects of situated learning experiences on a Biology field trip. The general idea behind such situated and experiential learning goes back to Kolb [6], who claims that learning has to take place in specific situations which provide rich contextual clues. In earlier work, it has been shown how this paradigm can be utilized in virtual learning environments, e.g. for increasing knowledge and skills about culture-specific gestures [9]. Transferred to a smart city learning scenario, it becomes crucial to integrate the city scape in the learning experience, making it an integral part of the learning.

(Mobile) Games for Learning Geometry Several games have already been developed for teaching geometry. Lai and White [7] present a collaborative learning game that is loosely based on Van Hiele's didactic approach. Students work together to create and learn about quadrilaterals by each controlling a single corner point of the shape. The main benefit of this approach is that it forces students to communicate about the geometric concepts and thus develop geometric reasoning throughout the learning episodes. In line with van Hiele's approach of playful learning, Vitale and colleagues [12] present a computer-based geometry learning tool and show that grounded integration, which is closely related to Gestalt principles, yields better learning results than a numerical approach. Wallner and Kriglstrein [13] report on a case study of a computer game for teaching geometry to elementary school children. In their concept they relate geometric shapes to real world objects found in nature in order to create a meaningful link between geometric concepts and the real world. As this is a desktop game this link is though only conceptual but not embodied and no results are presented.

A first embodied approach is presented in [14], describing a mobile mixed reality game for teaching about some geometric shapes (squares, rectangles, parallelograms). Players have to create the shapes by walking to the corner points in a real environment. There is though no direct connection between the environment and the geometric concepts. All of these games were desktop based or aimed at

\footnotetext{
${ }^{1}$ Smart City Learning Observatory: http://bit.ly/1DxH8sp (visited 2 July 2015).
} 
classroom teaching. This is actually in line with van Hiele's earlier observations of the disembodied and de-contextualized way of the standard curriculum. Also, math field trips are rarely heard of, making it not the prime target for mobile and location-aware games. A rare exception of a math field trip is the work presented in [10] on a project for collaborative learning of geometry with in- and outdoor learning activities. The concept combines field trips for data collection as well as class room based collaborative 3D construction tasks and can be seen as one inspiration for the work presented in this paper.

\section{From Van Hiele to Mobile Games}

Van Hiele argues against the disembodied way in which geometry is taught in standard textbooks and instead argues for a playful approach situating geometric concepts in the everyday experience of the children [4]. He describes five levels of geometry understanding that a learner passes through (see e.g. [8] for a concise overview): (1) Visualization: holistic recognition of shapes; (2) Analysis: Knowledge about features of shapes; (3) Abstraction: Understanding relationships between features and shapes; (4) Deduction: Understanding of axioms, definitions, and proofs; (5) Rigor: Understanding of formal aspects of deduction.

Although not undisputed (see e.g. [11]; [1]), the different levels provide a useful descriptive tool of progress in geometry learning. Based on these ideas, the following guidelines for design of the mobile experience have been derived: (i) focus on the necessity of play during learning; (ii) connection between the real world and the abstract geometric concepts; (iii) difficulty relates to level of geometric understanding of the students.

With the vision of smart city learning as the driving motivational factor, a game was envisioned that should be based on geometric shapes found in buildings around the city and utilize these shapes on location for learning about geometric concepts. In close collaboration with a Math teacher from a local school it was soon decided to integrate the mobile experience into the third grade class curriculum. Thus, the concept was changed to allow for a field trip for testing the ideas on smart city learning. Additionally, the games would then also be available in class for further use during Math teaching. The teacher contributed to the game design process from the beginning, providing regular reality checks for game concepts as well as gamification elements.

During the field trip, children start at the school. On their mobile devices they see a map (Fig. 1 a), which shows their chosen avatar moving on the map in real-time. Approaching one of the locations triggers a reaction on the device, revealing a task for unlocking the game related to this location (Fig. $1 \mathrm{~b}$ ). In our vision of smart city learning this would be a proactive behavior that could happen with any building in the city.

Calori and colleagues [2] analyzed learning trajectories on field trips and highlighted the ability of smart city technologies for triggering situated actions in-situ. The game design utilizes this advantage in the task of unlocking the location related games. This process is based on level 1 of van Hiele's approach (vi- 

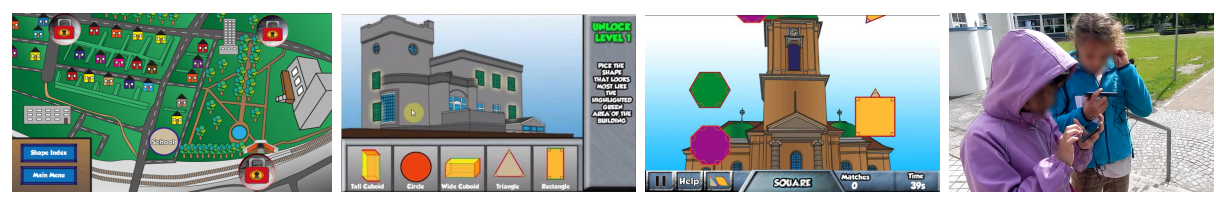

Fig. 1. From left to right: (a) in-game map with the three locations; (b) unlocking game (first location); (c) shape shoot; (d) children engaged in shape shoot.

sualization). The vicinity to buildings with a rich repertoire of geometric shapes triggers situated interactions with these shapes. The children have to compare geometric shapes of the building to prototypes presented to them. Figure 1 (b) shows an example, where the rectangular windows are highlighted and the child has to select the geometric shape that is most similar to this (the rectangle).

For each location, a distinct mini game has been developed that is related to levels 1 (L1) and 2 (L2) of van Hiele according to the age of the children (3rd grade):

- Shape memory: Variant of the well-known memory game. Children are exposed to graphic representations of shapes that have to be matched to the names (L1) or properties (L2) of the shapes. Example: rhombus (L1), equilateral triangle (L2).

- Shape shoot: Two- and three-dimensional shapes move randomly around the screen. A shape becomes a target when the name of the shape or its properties is displayed at the bottom of the screen (Fig. reffig:fig1 c). Shooting is then realized by tapping on the shape. Example: cube (L1), equilateral triangle (L2).

- Shape recognition: Children are presented with a 3D object and asked to signify which (and how many) 2D shapes are used to build this object. This also supports the acquisition of level 3 skills (abstraction), where students are supposed to understand relations between shapes and their properties. Example: a cube consists of six squares.

\section{Evaluation}

In our vision of smart city learning, learning becomes an integrated part of living in the city, where learning experiences are pro-actively triggered by the surroundings of the learner and in relation to contextual factors. This is envisioned to increase the learner's curiosity about the material and stimulate his/her interest to examine the underlying concepts in more depth and beyond the specific intervention. The evaluation was thus set up as a mixed measures approach, where a quantitative part was a pre-/post-test with a standard measurement tool for knowledge on geometry. The qualitative part combines video observations from the field trip with a semi-structured interview with the teacher, in order to get insights into the actual practices that evolved around the use of the game. The whole process is shown in Figure 2. 


$\left.\left.\left.\left.\left.\left.\begin{array}{l}\text { Pre- } \\ \text { Test }\end{array}\right\rangle \begin{array}{l}3 \text { day } \\ \text { break }\end{array}\right\rangle \begin{array}{l}\text { Game } \\ \text { day }\end{array}\right\rangle \begin{array}{l}1 \text { week } \\ \text { break }\end{array}\right\rangle \begin{array}{l}2 \text { weeks in } \\ \text { class play }\end{array}>\begin{array}{l}3 \text { day } \\ \text { break }\end{array}\right\rangle \begin{array}{l}\text { Post- } \\ \text { Test }\end{array}\right\rangle \begin{gathered}\text { Expert } \\ \text { interview }\end{gathered}$

Fig. 2. Evaluation Process

The hypothesis for the quantitative part is

H1: The mean of correct answers in the standardized geometry test will be higher after the intervention.

\subsection{Design}

12 pupils (age 8-9) from a 3rd grade class at Skipper Clement International School in Aalborg (Denmark) participated in the study. Six Android phones with a screen resolution of 480x800 pixels have been used. The game was developed in Unity3D. The pre- and post-test questionnaire was adapted from a standard van Hiele level test [11] by taking only questions into account that related to levels 1 to 3 of geometry understanding. It consisted of 19 questions.

First, the children's level of geometric understanding was assessed using the standard questionnaire (see also Figure 2 for an overview). After a break of three days, the field trip took place, where the children spend 3 hours exploring the surroundings of the school and playing the games. A week later, the phones were handed to the teacher for in-class use for a period of two weeks. After a break of three days, the post-test questionnaire was administered, followed by the expert interview with the teacher.

\subsection{Results and Discussion}

A paired-samples t-test was conducted to compare the number of correct answers in the pre- and post-test conditions. There was a significant increase in correct answers for the post-test: pre-test $(\mathrm{M}=6.36, \mathrm{SD}=1.80)$ vs. post-test $(\mathrm{M}=8.55$, $\mathrm{SD}=1.81), \mathrm{t}(10)=-3.52, \mathrm{p}<0.002$. In order to get insights about the levels of geometric understanding, additional t-tests were run for all sets of level specific questions. Significant differences were found for level 1 questions: pre-test $(\mathrm{M}=3.27, \mathrm{SD}=0.65)$ vs. post-test $(\mathrm{M}=4.55, \mathrm{SD}=1.04), \mathrm{t}(10)=-3.32, \mathrm{p}<0.004 . \mathrm{A}$ tendency for better scores was found for level 2 questions: pre-test $(\mathrm{M}=2.00$, $\mathrm{SD}=1.48)$ vs. post-test $(\mathrm{M}=2.64, \mathrm{SD}=0.92), \mathrm{t}(10)=-1.30, \mathrm{p}=0.112$. No significant result could be found for level 3 questions.

The hypothesis could not be rejected. Children performed significantly better after playing the game. The more detailed analysis revealed that this result is mainly depending on their performance on level 1 of geometry understanding. This could be expected for this age group. Additionally there is a tendency that children also got better with questions related to level 2 . 


\subsection{Qualitative Findings}

Observations are categorized according to three distinct phases: moving between locations, on location, and in class evaluation.

Moving Six recurring categories of behavior were identified:

(1) Excitement due to novelty: Children were very excited by the map and the location tracking. Seeing their avatar move on the map prompted comments and discussions between the children.

(2) Discussions about the game: Children started talking about their performance and were comparing badges.

(3) Discussion about the location: Children showed great excitement when they figured out which building they were going to. When getting close, some of them wanted to start running to the location.

(4) Positive appraisal statements: Such statements mostly occurred directly after leaving a location.

(5) Discussions about the surrounding architecture: Children started investigating the buildings along the way and talked about their similarity to the target buildings.

(6) Navigation: While walking, most conversations were about navigation. The children were looking around relating the real world to the map on their screen, using the avatar position to get an idea of where they were and how far it was to the location. The children were very goal oriented and talked about what buildings could be at the locations they were going to.

On Location The following recurring types of behavior were identified:

(1) Enthusiasm: The most prominent behavior was the enthusiasm shown when they unlocked a location or finished a level and got a badge.

(2) Immersion: Especially in the second location where children used headphones they became completely focused on the game. However, this also meant that they ignored their surroundings and did not spend much time with the actual building in this location.

(3) Frustration: For some children the geometric concepts in the game that relate to level 2 and 3 were hard to grasp.

In Class Back in class, the children were prompted by their teacher to give feedback regarding the game. All of them gave positive comments and said that they enjoyed the game. They were very interested in the game development process. When asked whether the children wanted to play the game again they all said yes. After a break of one week, the teacher re-introduced the mini-games during Math classes. Children were very motivated to play the game. The log files show an average playing time of 150 minutes per child.

Interview We summarize the findings that relate to the embodiment of learning and the resulting consequences.

(1) Field Trip and Location Awareness: The teacher points out the benefits of 
integrating material from the field (i.e. geometric shapes from the actual buildings) because it allows showing the material in a different way. This makes it more likely that children internalize what they are supposed to learn. The way in which the material was introduced on location in the game was important because it showed how the shapes fit together and how they are used in the real world. The children enjoyed the field trip and talked a lot about it afterwards. Especially the concept of unlocking the different locations was frequently discussed.

(2) Educational Value: According to the teacher, the game got the children curious about the world around them and interested in geometric shapes. After the intervention, children started telling stories about shapes that they found and started asking questions about things they did not understand in relation to geometry. Additionally, they were able to figure out how to combine shapes to make more complex ones, for instance combining rectangle and semicircle for arches. The children also showed more confidence in class and were able to explain things to the teacher that they hadn't been able before.

(3) Motivation: The teacher experienced that the children were motivated to play the game in class and when interacting with it that they stayed focused on it. In fact, he states that they were much more focused than they usually are when given traditional classroom tasks. According to the teacher, the children have a lot of "junk" on their phones that entertains them without any educational value. From his perspective, the game accomplished making the children excited about the schoolwork.

\section{Conclusion}

In this paper, we present smart city learning as an emerging field for applications of location-aware games. By drawing on the children's natural environment for contextualizing learning experiences, we expect to see better learning results and higher engagement in the learning topics. To investigate this claim, a locationaware game for geometry learning has been developed. The game is based on a renowned didactic approach and was developed in close collaboration with stakeholders from a local school, where it was also evaluated.

Test scores for the participating class were significantly better after intervention. Moreover, the children were motivated playing the game, which is apparent from the average playing time. Qualitative data from observations and an interview with the teacher revealed that the game was successful in increasing the children's curiosity about geometric concepts. During the field trip, they started looking for geometric shapes in the buildings they encountered on the way, afterwards in class they started to tell stories about shapes and discuss other shapes they discovered at home. Thus, this case study confirms that embodying abstract learning goals in the real-life experience of the children has a beneficial effect, increasing their curiosity about the underlying concepts.

According to the teacher, these effects were persistent over the whole period of the study, which is a good indication that the game concepts were suitable. 
Moreover, contextualizing geometry learning by integrating it with the children's natural environment, in this case the surroundings of the school, has proven successful and warrants further explorations of the concept of smart city learning.

\section{Acknowledgement}

We would like to thank Skipper Clement International School, Aalborg, and especially Benjamin Gilbert, for their support and collaboration.

\section{References}

1. Burger, W.F., Shaughnessy, J.M.: Characterizing the van Hiele Levels of Development in Geometry. Journal for Research in Mathematics Education 17(1), 31-48 (1986)

2. Calori, I.C., Rossitto, C., Divitini, M.: Understanding Trajectories of Experiences in Situated Learning Field Trips. Interaction Design and Architecture(s) Journal - IxD\&A 16, 17-26 (2013)

3. Giovannella, C., Iosue, A., Tancredi, A., Cicola, F., Camusi, A., Moggio, F., Baraniello, V., Carcone, S., Coco, S.: Scenarios for active learning in smart territories. Interaction Design and Architecture(s) Journal - IxD\&A 16, 7-16 (2013)

4. van Hiele, P.M.: Developing Geometric Thinking Through Activities That Begin With Play. Teaching Children Mathematics 6, 310-316 (1999)

5. Kamarainen, A.M., Metcalf, S., Grotzer, T., Browne, A., Mazzuca, D., Tutwiler, M.S., Dede, C.: EcoMOBILE: Integrating augmented reality and probeware with environmental education field trips. Computers \& Education 68, 545-556 (2013)

6. Kolb, D.A.: Experiential learning: experinece as the source of learning and development. Prentice Hall, Englewood Cliffs, NJ (1984)

7. Lai, K., White, T.: Exploring quadrilaterals in a small group computing environment. Computers \& Education 59, 963-973 (2012)

8. Mason, M.: The van Hiele levels of geometric undestanding. In: Professional Handbook for Teachers - Geometry: Explorations and Applications. McDougal Inc., Boston (1998)

9. Rehm, M., Leichtenstern, K.: Gesture-Based Mobile Training of Intercultural Behavior. Multimedia Systems 18(1), 33-51 (2012)

10. Spikol, D., Eliasson, J.: Lessons from Designing Geometry Learning Activities that Combine Mobiel and 3D Tools. In: Proceedings of the 6th International Conference on Wireless, Mobile, and Ubiquitous Technologies in Education. pp. 137-141 (2010)

11. Usiskin, Z.: Van Hiele Levels and Achievement in Secondary School Geometry. The University of Chicago, Chicago (1982)

12. Vitale, J.M., Swart, M.I., Black, J.B.: Integrating intuitive and novel grounded concepts in a dynamic geometry learning environment. Computers \& Education 72, 231-248 (2014)

13. Wallner, G., Kriglstein, S.: Design and Evaluation of the Educational Game DOGeometry - A case study. In: Proceedings of ACE (2011)

14. Wijers, M., Jonker, V., Kerstens, K.: MobileMath: the Phone, the Game and the Math. In: Proceedings of the 2nd European Game-Based Learning Conference (2008) 